\title{
DEVELOPMENT AND VALIDATION OF HPLC METHOD FOR THE DETERMINATION OF LOSARTAN IN HUMAN PLASMA
}

\author{
Uday Kiran Veldandi, Narsimha Reddy Yellu ", Nagulu Malothu, \\ Rama Krishna Devarakonda
}

Department of Pharmacology and Clinical Pharmacy, University College of Pharmaceutical Sciences; Kakatiya University, Warangal 506 009, Andhra Pradesh, INDIA.

\begin{abstract}
A simple, rapid and sensitive isocratic method for detection and quantification of losartan in plasma has been developed. The assay consisted of reversed HPLC with UV detection. Losartan chromatographed on a C18 column, mobile phase consisting of 50:50, acetonitrile and $0.1 \%$ of glacial acetic acid in water. The mobile phase was pumped at a flow rate of 1 . $0 \mathrm{ml} / \mathrm{min}$ and the eluent was monitored at $230 \mathrm{~nm}$. Valsartan $(20 \mu \mathrm{g} / \mathrm{ml})$ was used as internal standard. Sensitivity of the assay was $<50 \mathrm{ng} / \mathrm{ml}$. Intra-and inter-assay variations were $<$ land $<2 \%$ respectively. Recovery of losartan was $98-99 \%$. Using $500 \mu$ l of plasma sample, standard curves were linear from 0.05 to $0.5 \mu \mathrm{g} / \mathrm{ml}\left(r^{2}=0.9926\right)$. The assay has been successfully applied to measuring plasma concentrations of losartan in patients receiving a daily dose of losartan (12. 5-100mg). The validation data has been studied. This method provides sufficient reproducibility, sensitivity and specificity for clinical pharmacokinetic studies.
\end{abstract}

Key words: Determination, Losartan, human plasma, HPLC

' Corresponding Author: Dr . Y. Narsimha Reddy, Associate Professor Pharmacology \& Clinical Pharmacy, University College of Pharmaceutical Sciences, Kakatiya University, Warangal - 506009, India.

Work: +91-870-2461-433, Fax: +91-870-245-3508.

E-mail: yellu_nr@yahoo.com 


\section{INTRODUCTION}

Losartan is the first orally available angiotensin-receptor antagonist without agonist properties. Following oral administration, losartan is rapidly absorbed, reaching maximum concentrations $1-2$ hours post administration 11/. After oral administration approximately $14 \%$ of a losartan dose is converted to the pharmacologically active E 3174 metabolite $/ 2 \%$. Losartan is metabolized by the CYP3A4 and CYP2C9 isozymes $/ 3,4 /$. Losartan should penetrate the Renin-Angiotensin-Aldosterone System (RAAS). Heart, lung, blood vessels and other tissues are crucial for their effect, since cardio vascular homeostasis is not only regulated by a circulating (plasma) RAAS but also by local RAAS that synthesizes angiotensin II directly in the respective tissues $/ 5 /$. Based on the above facts we came to the conclusion that it is necessary to know the concentrations of losartan in plasma and other biological materials. For this we have developed a simple, rapid and sensitive HPLC-UV method for the determination of losartan in plasma. This paper describes development and validation of a reverse phase HPLC assay using liquid phase extraction and UV detector for measurement of losartan in plasma obtained from hy'pertensive patients treated chronically with losartan.

\section{MATERIALS AND METHODS}

\section{Standards and reagents}

Losartan and Valsartan were kindly provided by Sun Pharmaceuticals, Baroda and Vimta Labs, Hyderabad (India), respectively. Acetonitrile was HPLC grade and glacial acetic acid is analytical grade, purchased from Merck (Mumbai, India). Double distilled water was used throughout the study (Toshika water purifier, Germany).

\section{Apparatus and chromatographic condition}

The chromatographic apparatus was a Shimadzu liquid chromatography system equipped with a LT $10 \Lambda \mathrm{T}$ VP pump, a SPD 10A VP variable wavelength UV visible spectrophotometric detector and a Rheodyne 20 microliter loop injector system was used (Shimadzu, Kyoto, Japan). An INERTSIL ODS-3V C-18, 4. 6x250mm [Merck Ltd, Mumbai, India] 
chromatography column was used for analysis. The mobile phase consisted of acetonitrile, $0.1 \%$ of glacial acetic acid in water with the ratio of $50: 50$ respectively. The flow rate was $\mathrm{lml} /$ minute and the eluent was monitored spectrophotometrically at $230 \mathrm{~nm}$ at room temperature.

\section{Solutions}

A stock solution $(100 \mu \mathrm{g} / \mathrm{ml})$ of losartan and valsartan (IS) was prepared in water and methanol respectively. Working standard solutions were prepared daily by diluting the stock solution with water. All the stock solutions were stable at least two weeks at room temperature.

\section{Sample preparation}

To $0.5 \mathrm{ml}$ of human plasma in a $2 \mathrm{ml}$ eppendorf tube $100 \mu$ l of IS solution $(20 \mu \mathrm{g} / \mathrm{ml})$ and $100 \mu \mathrm{l}$ of losartan working standard solution were added. The tubes were vortex mixed for $50 \mathrm{sec}$ and then $0.5 \mathrm{ml}$ of acetonitrile was added. After mixing for $1 \mathrm{~min}$ and centrifuging at $13000 \mathrm{rpm}$ for $6 \mathrm{~min}$, supernatant was filtered by $0.45 \mu \mathrm{m}$ sample filter (Millipore filter). A volume of $20 \mu \mathrm{l}$ filtered supernatant was injected into the HPLC system.

\section{Calibration curve}

Working standard solutions were added to thawed plasma each day to yield concentrations ranging from 0.5 to $5 \mu \mathrm{g} / \mathrm{ml}$. Calibration curve for plasma was obtained by plotting peak area ratio of losartan and IS against losartan concentration.

\section{Recovery and accuracy}

The recovery was calculated by comparing peak area ratio obtained from plasma samples (QC samples) with area ratio that resulted after injecting standard solutions at the same theoretical concentration. 


\section{RESULTS}

Under the chromatographic condition described losartan and IS peaks were well resolved with retention time (RT) of $6.4 \pm 0.4$ and $9.4 \pm 0.3 \mathrm{~min}$, respectively (Fig. 3). The chromatogram of the blank plasma is shown in Fig. 2. No interfering peak was observed at retention times of losartan and IS. The calibration curve for determination of losartan in plasma was linear over range of $0.05-0.5 \mu \mathrm{g} / \mathrm{ml}$ and the corresponding equation was $y=0.2669 x-$ 0.0043 , where $y$ is the peak area ratio of losartan to IS and $x$ is the losartan concentration (Fig. 1). The reproducibility of the method was determined by repeating four replicate plasma samples on each of four separate days. According to the intra-day and inter-day data good precision and accuracy were observed over the entire concentration range. The CV values for within run and between run variability were less than $2 \%$ for all selected concentrations (Table 1). The Limit of Quantification (LOQ) of the method, defined as the minimum concentration that could be measured with $\mathrm{CV}<10 \%$, was found to be $0.05 \mu \mathrm{g} / \mathrm{ml}$. The recovery of drug was determined by comparing the peak area for losartan from spiked plasma and a standard solution of losartan in water with the same concentration. Three concentration ranges, $0.05,0.2$ and $0.4 \mu \mathrm{g} / \mathrm{ml}$, were investigated for recovery and accuracy studies. The mean recovery and accuracy of losartan were $98 \%$ and $99 \%$ respectively (Table 2 ).

Stability of QC samples was evaluated at room temperature after one and two weeks. In all conditions, samples preserved their potency $(>98 \%)$ during mentioned period.

\section{DISCUSSION}

The present method is able to measure the concentration of losartan in order to monitor the drug concentration in body fluid, determination of drug level in plasma for dose regulation and bioavailability studies. 


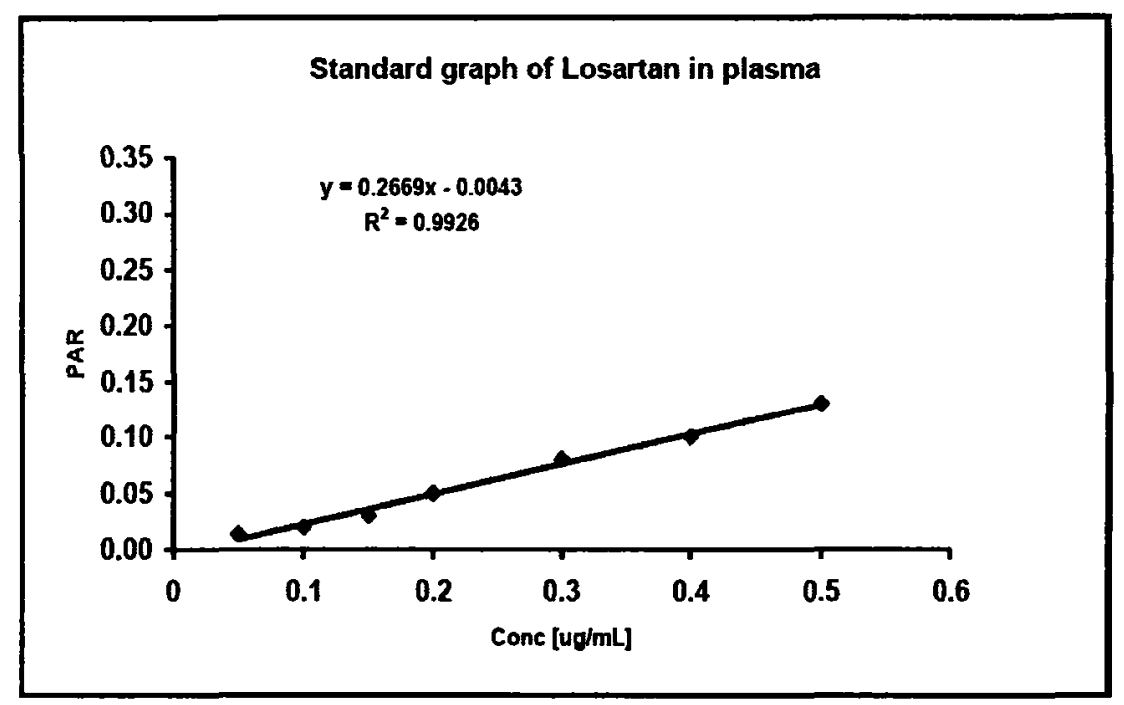

Fig 1: Linear standard curve determination of losartan in plasma

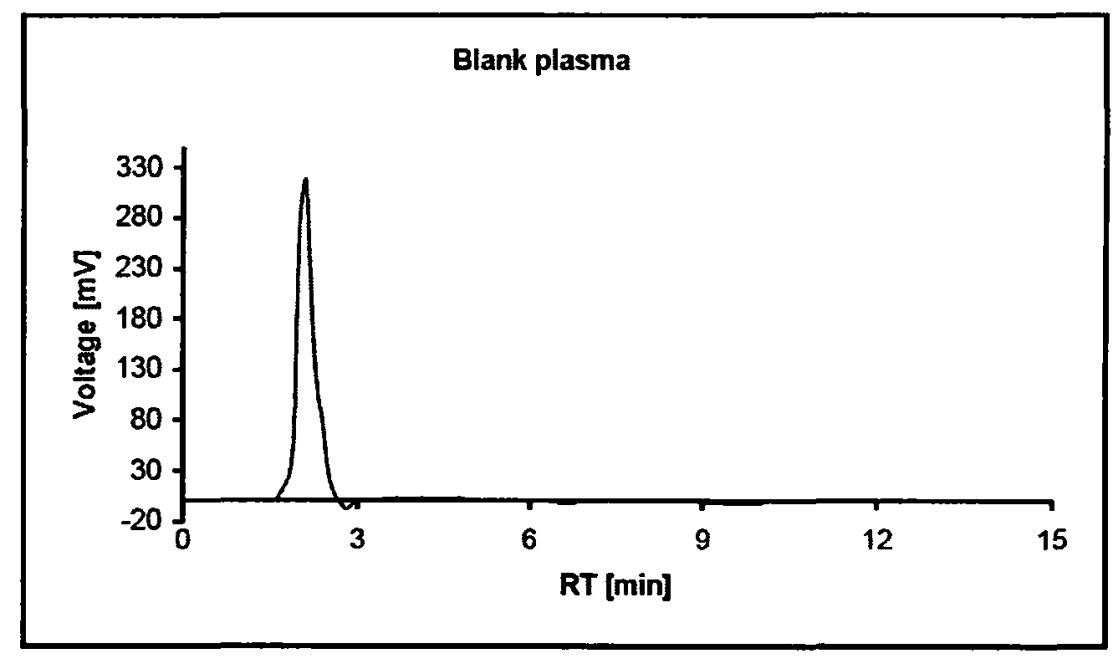

Fig 2: Human blank plasma 


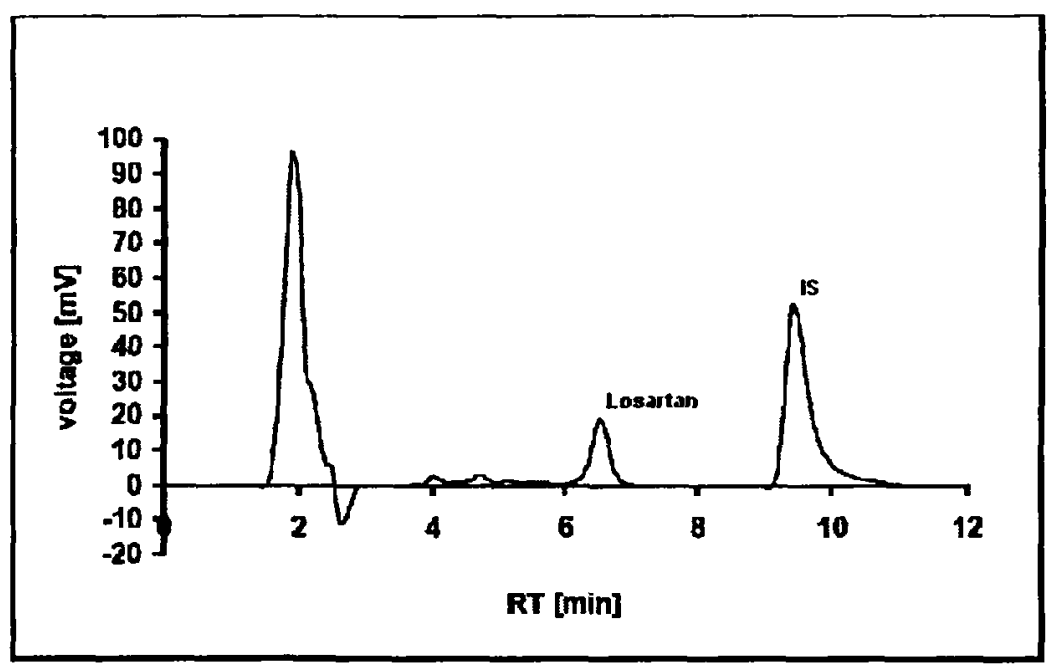

Fig 3: Losartan and IS in patient serum sample

Various methods of high-performance liquid chromatography for the determination of losartan in biological fluids have been described so far which differ in chromatography type (reverse phase or ion-pair chromatography) or detection system (UV or fluorescence) $16,8 /$. Reverse-phase high performance liquid chromatography with UV detection has been most recommended. In published methods the assay was achieved by long liquid-liquid and solid-phase extraction $/ 7,8,9$ / procedures. But an important point is that most of them are tedious and expensive because they use a large amount of material and have many experimental stages. Some of them are quite complex, lengthy and LOQ is not significant $/ 8 /$. Besides, they are not suitable for routine, quick drug monitoring at hospitals and reference laboratories. 
Table 1

\begin{tabular}{|c|c|c|c|c|c|}
\hline \multirow{2}{*}{$\begin{array}{l}\text { Spiked } \\
\text { concentration } \\
\text { (ng/ml) }\end{array}$} & \multirow[b]{2}{*}{ Day } & \multicolumn{4}{|c|}{ Measured Concentration } \\
\hline & & Mean (ng/ml) & SD & RSD & $\begin{array}{l}\% \\
\text { variation }\end{array}$ \\
\hline \multicolumn{6}{|c|}{ Inter-day variation } \\
\hline 50 & 1 & 49.130 & 0.376 & 0.765 & 1.74 \\
\hline 50 & 2 & 49.180 & 0.100 & 0.203 & 1.64 \\
\hline 50 & 3 & 49.540 & 0.096 & 0.194 & 0.92 \\
\hline 50 & 4 & 49.790 & 0.030 & 0.060 & 0.42 \\
\hline 200 & 1 & 198.980 & 0.650 & 0.327 & 0.51 \\
\hline 200 & 2 & 199.310 & 0.120 & 0.060 & 0.34 \\
\hline 200 & 3 & 199.040 & 0.050 & 0.025 & 0.48 \\
\hline 200 & 4 & 199.400 & 0.960 & 0.481 & 0.30 \\
\hline 400 & 1 & 398.990 & 0.960 & 0.241 & 0.25 \\
\hline 400 & 2 & 399.050 & 0.069 & 0.017 & 0.24 \\
\hline 400 & 3 & 398.750 & 0.870 & 0.218 & 0.31 \\
\hline 400 & 4 & 398.650 & 0.050 & 0.013 & 0.34 \\
\hline \multicolumn{6}{|c|}{ Intra-day variation } \\
\hline 50 & 1 & 49.900 & 49.800 & 49.700 & 0.20 \\
\hline 200 & 1 & 199.800 & 199.560 & 197.980 & 0.10 \\
\hline 400 & 1 & 399.810 & 398.790 & 399.560 & 0.05 \\
\hline
\end{tabular}

SD: Standard deviation, RSD: Relative standard deviation and mean value of 4 determinations

In the present method no extraction is needed because it involves only simple steps like deproteinization/dilution and the addition of acetonitrile. A clean chromatogram results using acetonitrile which is a suitable deproteinization agent for losartan and probably other angiotensin II receptor antagonists. Although the sampling procedure was simple in some published methods, in the majority of the reported methods expensive fluorescence detectors /9/ and LCMS/MS /10/ were used, facilities that are not commonly available in every laboratory. Because these methods are labor expensive, requiring extensive sample extraction procedures, they cannot be used for routine screening of numerous samples. The present method is adequately sensitive for routine use with UV detection. If necessary, the sensitivity of the method can be increased by raising the plasma volume and injection volume. 
Table 2

Assessment of Recovery and Accuracy determination of Losartan in human plasma

\begin{tabular}{|l|l|l|l|}
\hline Substance & Concentration & $\begin{array}{l}\text { Recovery (\%) } \\
\text { Mean } \text { +SD }\end{array}$ & $\begin{array}{l}\text { Accuracy (\%) } \\
\text { Mean } \pm \text { SD }\end{array}$ \\
\hline Losartan & $50(\mathrm{ng} / \mathrm{ml})$ & $98.82 \pm 062$ & $99.88 \pm 0.5$ \\
\hline Losartan & $200(\mathrm{ng} / \mathrm{ml}))$ & $99.59 \pm 0.1$ & $100.05 \pm 008$ \\
\hline Losartan & $400(\mathrm{ng} / \mathrm{ml})$ & $99.71 \pm 0.04$ & $100.01 \pm 0.04$ \\
\hline Internal Standard & $20(\mu \mathrm{g} / \mathrm{ml})$ & $97.01 \pm 0.02$ & $95.69 \pm 1$ \\
\hline
\end{tabular}

\section{CONCLUSION}

$A$ one step sample extraction of losartan from plasma and an improved method for determination of losartan in plasma are reported in this study. Compared to previously published methods, the suggested method is considerably more simple, rapid, reliable and sensitive. The HPLC technique based on UV detection is suitable for determination of small amounts of losartan with good accuracy and reproducibility. A simple sample preparation procedure and a relatively short chromatographic time make this method suitable for processing of multiple samples in a limited amount of time for pharmacokinetic studies

\section{REFERENCES}

1. A. S. Domenic, W. B Gehr and G. Siddhartha, Clin. Pharmacokinet. 44, 797-814 (2006).

2. M. W. Lo, M. R. Goldberg, J. B. Crea, H. Lu, C. I. Furtek, T. D. Bjornsson. Clin. Pharmacol. Ther. 58, 641-649(1995).

3. K. M. Kaukonen, K. T. Olkkola, P. J. Neuvonen. Eur. J. Clin. Pharmacol.. 53, 445-449 (1998).

4. K. M. Willianson, J. H. Patterson, R. H. McQueen, K. F. Adams, J. A. Pieper. Clin. Pharmacol.Tther. 63 , 316-323 (1998).

5. J. E. Rodgers, J. H. Patterson. Am J Health Syst Pharm, 58, 671-683 (2001). 
6. A. R. Michael, C. I. Furtek, M. W. Lo. J. Pharmaceut. Biomed Anal. 15, 1021-1029 (1997).

7. A. Soldner, S. L. Hildegard, E. Mutschler . J. Pharmaceut. Biomed. Anal. 16, 863-873 (1998).

8. C. I. Furtek, M. W. Lo. J. Chromatogr. Biomed. Appl. 573 , 295-301 (1992).

9. K. F. Pollen, J. Angela , J. S. . Gareth, F. Debbra , P. Timothy. Int. J. Pharmaceut. 204, 17-22 (2000).

10. N. Ferreiros, S. Dresen , A. Rosa Maria., W. Weinmann. Therapeutic Drug Monitoring, 29 (6), 824-834 (2007). 